Gut, $1985,26,625-628$

\title{
HLA-DR antigens in primary biliary cirrhosis: lack of association
}

\author{
M F BASSENDINE, P J DEWAR, AND O F W JAMES \\ From the Department of Medicine, Freeman Hospital and Regional Transfusion Centre, General Hospital, \\ Newcastle upon Tyne
}

SUMmARY A study of HLA-DR antigens in 75 patients with primary biliary cirrhosis has been carried out in order to test the hypothesis that genetic factors related to genes controlling immune responses might be important in the pathogenesis of primary biliary cirrhosis. The frequencies of HLA-DR locus antigens was not significantly different from those in 200 normal controls, nor were those of tissue antigens on the A and B loci. No HLA-DR antigen was significantly associated with the appearance of granulomata on liver biopsy (possibly good prognosis) or with raised serum bilirubin (possibly bad prognosis); nor was there any association between any HLA-DR antigen and adverse reactions to D-penicillamine treatment in 17 patients with such adverse reactions. It is concluded that genetic traits related to HLA antigens studied are probably not important in the aetiology of the disease.

Primary biliary cirrhosis is a chronic cholestatic disease of unknown aetiology which affects predominantly middle aged women. It is characterised by many immunological abnormalities including the presence of autoantibodies in the serum, ${ }^{1}$ the presence of lymphocytic infiltrates and granulomas in the liver, hypergammaglobinaemia with high concentrations of $\mathrm{IgM}^{3}$ and circulating monomeric (7S) $\mathrm{IgM},{ }^{4}$ high concentrations of circulating immune complexes ${ }^{5}$ and an impaired suppressor cell activity. ${ }^{4}$ It is frequently associated with other 'autoimmune' disorders such as Sjögren's syndrome, rheumatoid arthritis, Hashimoto's thyroiditis and scleroderma. ${ }^{6}$ The occasional familial occurrence of primary biliary cirrhosis ${ }^{7-10}$ and the increased incidence of certain immunological abnormalities in family members of patients with primary biliary cirrhosis ${ }^{11-13}$ indicates that genetic factors may be important in its pathogenesis. Such genetic traits could be related to genes controlling immune responses. Many diseases with immunological determinants are associated with certain HLA antigens coded for by genes in the major histocompatibility complex. For these reasons there could be a relationship between primary biliary cirrhosis and one or more HLA antigens. A

Address for correspondence: Dr O F W James. Medical Unit 1. Freeman Hospital, Newcastle upon Tyne NE7 7DN.

Received for publication 24 July 1984 previous study in British patients with primary biliary cirrhosis, however, found no association with HLA antigens on the A and B loci. ${ }^{14}$ The subsequent demonstration of HLA-DR antigens ${ }^{15}$ and evidence that these antigens appear to play a major role in cellular interactions between $\mathrm{T}$ and $\mathrm{B}$ lymphocytes $^{16}{ }^{17}$ has raised the possibility that HLADR antigens may be associated with susceptibility to primary biliary cirrhosis. Two recent reports of small series from Spain (21 patients) ${ }^{18}$ and Japan $(22 \text { patients })^{19}$ have suggested an association between HLA-DR3 and DR2 respectively. Furthermore an association has been found between other 'autoimmune' disorders which occur in primary biliary cirrhosis and HLA-DR antigens. ${ }^{20}$ We have therefore undertaken a large study to investigate whether any of the HLA-DR loci are associated with primary biliary cirrhosis in British patients.

The clinical spectrum of primary biliary cirrhosis is broad $^{6}$ and the rate at which the disease progresses varies widely. The factors determining this progression are ill understood and genetic components may interact with each other and the environment to produce full clinical expression of the disease. It has been shown that raised serum bilirubin concentrations in primary biliary cirrhosis reflect a poor prognosis ${ }^{21} 22$ and suggested that patients with focal granulomatous lesions in their liv- 
ers have a good prognosis. ${ }^{23}$ We have analysed our results to find out whether either of these prognostic factors are associated with any HLA-DR antigen. D-penicillamine has been advocated in the treatment of primary biliary cirrhosis ${ }^{24}$ but a high incidence of unwanted effects has been encountered. $^{2526}$ Toxicity of D-penicillamine in rheumatoid arthritis has been reported to be associated with HLA-DR3 antigens, ${ }^{27}$ so we have also analysed our results to see if adverse reactions to Dpenicillamine in primary biliary cirrhosis may similarly be under genetic control.

\section{Methods}

\section{PATIENTS}

The diagnosis of primary biliary cirrhosis was established on standard biochemical, immunological, and histological criteria. ${ }^{6}$ Serial sections from each liver biopsy specimen were examined after routine staining and assessed for the presence of granulomas. Up to four biopsies were available for assessment on each patient. The serum bilirubin measurement recorded for the purpose of evaluating possible prognosis was the lower of two values taken six months apart, the second being recorded at the time of tissue typing. Seventy five unrelated primary biliary cirrhosis patients were typed for HLA-DR antigens. The lymphocytes of 105 patients, including those typed for $D$ antigens, were also examined for 13 HLA-A and 20 HLA-B locus antigens. The frequency of these antigens was compared with a control group of 200 unrelated 'normal healthy' persons drawn randomly from the same local population.

The serologically defined HLA-DR antigens were shown in a lymphocytotoxic test on B lymphocytes separated from peripheral blood as previously described. ${ }^{28}$,The lymphocytotoxic test was a modification of the technique suggested by Mittal et $a .^{29}$ The antisera used had been standardised against cells typed with International Workshop antisera.

The statistical significance of differences in antigen frequencies between patient groups, subgroups and controls was calculated using the $\chi^{2}$ test and Fishers' exact test was applied where appropriate, and the $p$ values corrected for the number of antigens measured.

\section{Results}

In primary biliary cirrhosis the frequencies of the HLA-DR locus antigens were not significantly different from those in the normal controls (see Table 1). None of the HLA-A or B antigen frequencies
Table 1 Frequency and percentage of HLA-DR locus antigens in unrelated primary biliary cirrhosis patients and normal controls.

\begin{tabular}{|c|c|c|c|c|c|}
\hline \multirow{2}{*}{\multicolumn{2}{|c|}{$H L A-$}} & \multicolumn{2}{|c|}{$\begin{array}{l}\text { Normal controls } \\
(n=200)\end{array}$} & \multicolumn{2}{|c|}{$\begin{array}{l}\text { PBC patients } \\
(n=75)\end{array}$} \\
\hline & & No & $\%$ & No & $\%$ \\
\hline \multirow[t]{8}{*}{ DR } & 1 & 20 & 10 & 9 & 12 \\
\hline & 2 & 63 & 31 & 17 & 27 \\
\hline & 3 & 54 & 27 & 12 & 16 \\
\hline & 4 & 70 & 35 & 31 & 41 \\
\hline & 5 & 23 & 11 & 3 & 4 \\
\hline & 6 & 34 & 17 & 9 & 12 \\
\hline & 7 & 43 & 21 & 25 & 33 \\
\hline & 8 & 6 & 3 & 5 & 7 \\
\hline
\end{tabular}

PBC $=$ primary biliary cirrhosis.

in the patient groups showed any significant differences from the normal controls. No HLA-DR antigen was significantly associated with the two factors which are thought to reflect the prognosis of primary biliary cirrhosis (see Table 2). No association with any HLA-DR antigen was found in the 17 patients receiving D-penicillamine who developed drug related adverse effects; in particular none of the four patients who developed significant proteinuria $(>2 \mathrm{~g} / 24$ hours) were positive for HLA-DR3 antigens. (See Table 3).

\section{Discussion}

'Autoimmune' diseases may be divided into organspecific and non-organ specific polysystemic disease such as primary biliary cirrhosis. An HLADR linkage is now well documented in many organ-specific autoimmune disorders such as those

Table 2 Frequency and percentage of $H L A-D R$ locus antigens in groups of primary biliary cirrhosis patients with good (granuloma) and poor (bilirubin $>2 \times N$ ) prognostic features.

\begin{tabular}{|c|c|c|c|c|c|}
\hline \multirow{2}{*}{\multicolumn{2}{|c|}{$H L A-$}} & \multicolumn{2}{|c|}{$\begin{array}{l}\text { PBC patients with } \\
\text { granuloma }(n=22)\end{array}$} & \multicolumn{2}{|c|}{$\begin{array}{l}\text { PBC patients with } \\
\text { bilirubin } 2 \times N(n=25)\end{array}$} \\
\hline & & No & $\%$ & No & $\%$ \\
\hline \multirow[t]{8}{*}{ DR } & 1 & 3 & 14 & 3 & 12 \\
\hline & 2 & 5 & 23 & 6 & 24 \\
\hline & 3 & 4 & 18 & 3 & 12 \\
\hline & 4 & 10 & 45 & 10 & 40 \\
\hline & 5 & 1 & 4 & - & - \\
\hline & 6 & 3 & 14 & 3 & 12 \\
\hline & 7 & 9 & 41 & 10 & 40 \\
\hline & 8 & 1 & 4 & 1 & 4 \\
\hline
\end{tabular}

PBC = primary biliary cirrhosis. 
Table 3 Frequency and percentage of $H L A-D R$ locus antigens in primary biliary cirrhosis patients treated with D-penicillamine who did and did not develop side effects.

\begin{tabular}{|c|c|c|c|c|c|}
\hline \multirow{3}{*}{\multicolumn{2}{|c|}{$H L A-$}} & \multicolumn{4}{|c|}{$P C B$ patients treated with $D$-penicillamine } \\
\hline & & \multicolumn{2}{|c|}{$\begin{array}{l}\text { Side effects } \\
(n=17)\end{array}$} & \multicolumn{2}{|c|}{$\begin{array}{l}\text { No side effects } \\
(n=14)\end{array}$} \\
\hline & & No & $\%$ & No & $\%$ \\
\hline \multirow[t]{8}{*}{ DR } & 1 & 1 & 6 & 4 & 29 \\
\hline & 2 & 3 & 18 & 1 & 7 \\
\hline & 3 & 3 & 18 & 1 & 7 \\
\hline & 4 & 7 & 41 & 8 & 57 \\
\hline & 5 & 1 & 6 & - & - \\
\hline & 6 & 3 & 18 & 2 & 14 \\
\hline & 7 & 4 & 23 & 6 & 43 \\
\hline & 8 & - & - & - & - \\
\hline
\end{tabular}

$\mathrm{PBC}=$ primary biliary cirrhosis.

affecting endocrine glands ${ }^{30}$ and lupoid chronic active hepatitis. ${ }^{31} \mathrm{~A}$ possible association of primary biliary cirrhosis with two different HLA-DR loci has been reported ${ }^{18}{ }^{19}$ but our data are at variance with those previous reports. This much larger study has failed to confirm a significant deviation of HLA-DR antigens in primary biliary cirrhosis patients, suggesting that the previous small studies may have fallen into a Type I error.

Immunological abnormalities such as mitochrondrial antibodies in the serum may be present in primary biliary cirrhosis for many years without the appearances of overt clinical disease. ${ }^{6}$ Although the importance of the presence of granulomas in the liver biopsy, regardless of histological stage, as being indicative of a good prognosis in primary biliary cirrhosis ${ }^{23}$ has subsequently been challenged, ${ }^{32}$ the present study provides no support for the hypothesis that, they are associated with any HLA-DR locus. By dividing the patients into those with a raised serum bilirubin and those with a normal or near normal level (Table 2) we have attempted to identify a group with a poor prognosis. Admittedly some of the individuals in whom bilirubin was recorded below $34 \mu \mathrm{mol} / 1(2 \times$ normal) may subsequently progress to a higher bilirubin concentration but we feel that the broad division into a group with an acknowledged poor prognosis - those with raised serum bilirubin ${ }^{21} 32$ vs those with a far better prognosis is useful. Again no association between raised serum bilirubin and an HLA-DR antigen has been found. In the present study there is thus no evidence that any gene (or factor) associated with the HLA-DR locus protects against disease progression or conversely is associated with increased susceptibility to severe disease. If primary biliary cirrhosis does result from a failure of the regulatory system of the immune response, its genetic control appears to be localised outside the HLA-DR region, or its allele is in linkage equilibrium with HLA-DR antigens.

Our data are also at variance with a previous report of a trend toward the development of proteinuria during treatment with D-penicillamine in rheumatoid arthritis patients with the HLA-DR W3 locus. Only four of our D-penicillamine treated primary biliary cirrhosis patients developed significant proteinuria and none were HLA-DR3 positive. No significant association was found with any other drug related adverse reaction such as the development of systemic lupus erythematosus. We are thus unable to support the hypotheses that primary biliary cirrhosis disease susceptibility or immunologically mediated drug toxicity in this disorder are controlled by genes in the HLA-DR region of the histocompatibility system. The results provide some evidence against there being an important genetic basis to the disease in most patients.

\section{References}

1 Doniach D, Roitt IM, Walker JG, Sherlock S. Tissue antibodies in primary biliary cirrhosis, active chronic hepatitis, cryptogenic cirrhosis and in primary biliary cirrhosis and other liver disease and their implications. Clin Exp Immunol 1966; 1: 237-62.

2 Scheuer PJ. Biliary disease. Chronic hepatitis. In: Scheuer PJ ed. Liver biopsy interpretation. Baltimore: Williams \& Wilkins, 1973: 25-39, 66-73.

3 MacSween RNM, Horne HW, Moffat AJ, Hughes HM. Serum protein levels in primary biliary cirrhosis. J Clin Pathol 1972; 25: 789-94.

4 James SP, Elson CO, Strober W. Abnormal regulation of immunoglobulin synthesis in vitro in primary biliary cirrhosis. Gastroenterology 1980; 79: 242-8.

5 Thomas HC, Potter BJ, Sherlock S. Is primary biliary cirrhosis an immune complex disease? Lancet 1977; 1: 1278-81.

6 James OFW, Macklon AF, Watson AJ. Primary biliary cirrhosis - a revised clinical spectrum. Lancet 1981; 1: 1278-81.

7 Brown R, Clark ML, Doniach D. Primary biliary cirrhosis in brothers. Postgrad Med J 1975; 51: 110-5.

8 Chohan MR. Primary biliary cirrhosis in twin sisters. Gut 1973; 14: 213-4.

9 Douglas JG, Finlayson NDC. Are increased individual susceptibility and environmental factors both necessary for the development of primary biliary cirrhosis. Br Med J 1979; 2: 419-20.

10 Tong MJ, Nies KM, Reynolds TB, Quismorio FB. Immunological studies in familial primary biliary cirrhosis. Gastroenterology 1976; 71: 365-7 
11 Feizi T, Naccarato R, Sherlock S, Doniach D. Mitochondrial and other tissue antibodies in relatives of patients with primary biliary cirrhosis. Clin Exp Immunol 1972; 10: 609-22.

12 Galbraith RM, Smith M, MacKenzie RM et al. High prevalence of seroimmunologic abnormalities in relatives of patients with chronic active hepatitis or primary biliary cirrhosis. $N$ Engl J Med 1974; 290: 63-9.

13 Jaup BH, Zettergren LSW. Familial occurrence of primary biliary cirrhosis associated with hypergammaglobulinaemia in descendents: a family study. Gastroenterology 1980; 78: 549-55.

14 Galbraith RM, Eddleston ALWF, Smith MGM et al. Histocompatibility antigens in active chronic hepatitis and primary biliary cirrhosis. $\mathrm{Br}$ Med J 1974; 2: 604-5.

15 Winchester RJ, Fu SM, Wernet $\mathrm{H}$ et al. Recognition by pregnancy serums of non HLA alloantigens selectively expressed on B lymphocytes. J Exp Med 1975; 141: 924-9.

16 Hanson GS, Rubin B, Sorensen ST, Svejgaard A. Importance of HLA-D antigens for the cooperation between human monocytes and T-lymphocytes. Eur $J$ Immunol 1978; 8: 520-5.

17 Engleman EG, McMichael AJ, Batey ME, McDevitt HO. A suppressor $T$ Cell of the mixed lymphocyte reaction in man specific for the stimulating alloantigen. Evidence that identity of HLA-D between suppressor and responder is required for suppression. $J$ Exp Med 1978; 147: 137-46.

18 Ercilla G, Pores A, Arriaga F, Briguera M, Castillo R, Rodes J, Vives J. Primary biliary cirrhosis associated with HLA-DRW 3. Tissue Antigents 1979; 14: 449-52.

19 Miyamori H, Kato Y, Kobayashi K, Hattori N. HLA Antigens in Japanese patients with primary biliary cirrhosis and autoimmune hepatitis. Digestion 1983; 26: 213-7.

20 Stastny P. Association of the B-cell alloantigen DR W4 with rheumatoid arthritis. $N$ Engl J Med 1978; 298: 869-71.

21 Shapiro JM, Smith H, Schaffner F. Serum bilirubin: a prognostic factor in primary biliary cirrhosis. Gut 1979; 20: $137-40$.

22 Christensen E, Crowe J, Doniach D et al. Clinical pattern and course of disease in primary biliary cirrhosis based on an analysis of 236 patients. Gastroenterology 1980; 78: 236-46.

23 Lee RG, Epstein O, Jauregini H, Sherlock S, Scheuer PJ. Granulomas in primary biliary cirrhosis: a prognostic feature. Gastroenterology 1981; 81: 983-6.

24 Epstein O, Lee RG, Boss AM et al. D-Penicillamine treatment improves survival in primary biliary cirrhosis. Lancet $1981 ; 1: 1275-7$.

25 Matloff DS, Alpert E, Resnick RH, Kaplan MM. A prospective trial of D-penicillamine in Primary Biliary Cirrhosis. N Engl J Med 1982; 306: 319-26.

26 Macklon AF, Bassendine MF, James OFW. Controlled trial of D-penicillamine in primary biliary cirrhosis: incidence of side effects and relation to dose. Hepatology 1982; 2: 166.

27 Wooley PH, Griffin J, Parayi GS, Batchelor JR, Welsh KI, Gibson TJ. HLA-DR antigens and toxic reaction to sodium aurothiomolate and $D$ penicillamine in patients with rheumatoid arthritis. $N$ Engl J Med 1980; 303: 300-2.

28 Dewar PJ. HLA antigens. Clin Rheum Dis 1983; 9: 93-116.

29 Mittal KK, Mickey MR, Surgal DP, Terasaki PI. Serotyping for homotransplantation XVIII. Refinement of microdoplet lymphocyte cytotoxicity test. Transplantation 1968; 6: 913-27.

30 Grumet FC, Payne RO, Konishi J, Mori T. HLA-A antigens as markers for disease susceptibility and autoimmunity in Graves disease. J Clin Endocrinol Metab 1974; 39: 1115-9.

31 Mackay IR, Tait BD. HLA Associations with Autoimmune type chronic active hepatitis: identification of B8-DRW3 haplocyte by family studies. Gastroenterology 1980; 79: 95-8.

32 Roll J, Boyer JL, Barry D, Klatskin. The prognostic importance of clinical and histological features in a symptomatic and symptomatic primary biliary cirrhosis. N Engl J Med 1983; 308: 1-7. 